\title{
High g-Force Rollercoaster Rides Induce Sinus Tachycardia but No Cardiac Arrhythmias in Healthy Children
}

\author{
Guido E. Pieles ${ }^{1,2} \cdot$ Victoria Husk $^{1} \cdot$ Teresa Blackwell $^{1} \cdot$ Deirdre Wilson $^{1}$ • \\ Simon M. Collin ${ }^{3}$ Craig A. Williams ${ }^{4}$ A. Graham Stuart ${ }^{1}$
}

Received: 13 June 2016/Accepted: 7 September 2016/Published online: 21 September 2016

(C) The Author(s) 2016. This article is published with open access at Springerlink.com

\begin{abstract}
Theme park operators and medical professionals advise children with heart conditions against using rollercoaster rides, but these recommendations are not evidencebased. The underlying assumption is that the combination of adrenergic stimulation through stress and acceleration might trigger arrhythmias in susceptible individuals. We conducted a cross-sectional observational study to assess heart rate and rhythm in healthy children during commercial rollercoaster rides. Twenty healthy children ( 9 male) aged 11-15 (mean $13.3 \pm 1.4$ ) years underwent continuous heart rate and rhythm monitoring (2-lead ECG) from $5 \mathrm{~min}$ before until $10 \mathrm{~min}$ after each of 4 high speed $\left(>50 \mathrm{~km} \mathrm{~h}^{-1}\right)$, high g-force $(>4)$ commercial rollercoaster rides. Total recording time was $13 \mathrm{~h} 20 \mathrm{~min}$. No arrhythmic events were detected. Resting heart rate was $81 \pm 10$ $\mathrm{b} \min ^{-1}$ and increased to $158 \pm 20 \mathrm{~b} \cdot \mathrm{min}^{-1}$ during rides. The highest mean HR $\left(165 \pm 23 \mathrm{~b} \mathrm{~min}^{-1}\right)$ was observed on the ride with the lowest g-force ( $4.5 \mathrm{~g}$ ), but one of the highest speeds $\left(100 \mathrm{~km} \mathrm{~h}^{-1}\right)$. Anticipatory tachycardia $\left(126 \pm 15 \mathrm{~b} \mathrm{~min}^{-1}\right)$ within 5 min was frequently observed. A $10 \mathrm{~min}$ recovery $\mathrm{HR}\left(124 \pm 17 \mathrm{~b} \mathrm{~min}^{-1}\right)$ was $56 \%$
\end{abstract}

\section{Guido E. Pieles}

guido.pieles@bristol.ac.uk

1 Bristol Congenital Heart Centre, The Bristol Heart Institute, University Hospitals Bristol NHS Foundation Trust, Bristol, UK

2 National Institute for Health Research (NIHR) Cardiovascular Biomedical Research Unit, Bristol Heart Institute, University of Bristol, Bristol, UK

3 Centre for Child and Adolescent Health, School of Social and Community Medicine, University of Bristol, Bristol, UK

4 Children's Health and Exercise Research Centre, College of Life and Environmental Sciences, University of Exeter, Exeter, UK greater than resting HR. The speed and g-force experienced on roller coasters induce sinus tachycardia but do not elicit pathological arrhythmias in healthy children.

Keywords Cardiology · Arrhythmia $\cdot$ Rollercoaster . g-force

\section{Introduction}

Theme parks are popular with children and adults. In the UK, the three biggest theme parks had 6.9 million visitors in 2014 , a $4.7 \%$ increase compared to 2013 [1]. Attendance at a theme park is regarded as safe, with an injury risk requiring hospitalisation of 1 in 24 million [2]. In the US, approximately 40 deaths over 10 years were attributable to rollercoaster rides, five of which were in children with a suspected cardiac or respiratory cause [3]. Although theme park ride operators and medical professionals advise children with heart conditions against using the rides, these recommendations are based on consensus, not on scientific evidence.

A primary concern is that the combination of adrenergic stimulation through stress and acceleration (g-force; g) experienced on roller coasters might trigger arrhythmias in susceptible individuals [4]. Studies from aviation science have demonstrated that high $\mathrm{g}$ can provoke atrial and ventricular ectopics, paroxysmal supraventricular tachycardia, paroxysmal atrial fibrillation but also sustained ventricular tachycardias [5]. Research on the cardiovascular effect of rollercoaster rides has been confined to adults participating in older style rides which have relatively low g generation. However, these studies have reported asymptomatic supraventricular arrhythmias, nonsustained ventricular tachycardia and even aortic 
dissection [6, 7]. To the best of the authors knowledge, there have been no reported studies on the cardiovascular effects of rollercoaster rides in children or adolescents. This is the first study to investigate the effect of modern high $\mathrm{g}$ rollercoaster rides on heart rhythm in healthy children.

\section{Patients and Methods}

Twenty healthy children ( 9 male), mean age of $13.3 \pm 1.5$ years underwent a cardiovascular examination, medical and family history questionnaire and 12-lead ECG prior to the study. Patients with an abnormal cardiovascular examination, history or ECG were excluded from the study. Whilst at the theme park, participants wore a 2-lead ambulatory ECG monitor (R test evolution 4, Novacor $($ )). After manual activation, data were recorded continuously from $5 \mathrm{~min}$ before rollercoaster rides (anticipatory period) until $10 \mathrm{~min}$ after the ride (recovery period) on four rides. The maximum $\mathrm{g}$ was $5 \mathrm{~g}$ (mean $4.7 \pm 0.2 \mathrm{~g}$ ), maximum speed was $130 \mathrm{~km} \mathrm{~h}^{-1}$ (mean $92 \pm 48.2 \mathrm{~km} \mathrm{~h}^{-1}$ ), and the average ride time was $82 \pm 36 \mathrm{~s}$ with breaks of a minimum of 45 min between rides (Table 1). Data were analysed using dedicated offline software (RT Soft Ultima, Novacor(C) by one investigator trained in paediatric ECG analysis (GEP), blinded to the type of ride and identification of participant.

\section{Statistical Analysis}

All data are presented as mean (SD) and mean difference [95\% CI] unless otherwise stated. The mean resting, anticipatory, maximum and recovery heart rates (HR) were compared with baseline HR for each ride using Student's t test. Random effects linear regression models adjusted for age and resting HR were used to investigate differences in maximum, recovery and anticipatory HR by ride and by sex. All analyses were performed using Stata (StataCorp 2013. Stata Statistical Software: Release 13. College Station, TX: StataCorp LP).

\section{Results}

The baseline 12-lead ECG showed a mean resting HR of $81 \pm 10 \mathrm{~b} \mathrm{~min}^{-1}$. No baseline 12-lead ECG abnormalities were detected. During the data collection at the theme park, total ECG recording time was $13 \mathrm{~h} 20$ min with 59 individual ride recordings. Nineteen out of twenty participants experienced sinus tachycardia (HR $>100 \mathrm{~b} \mathrm{~min}^{-1}$ ), with 214 episodes of tachycardia recorded (Table 1; Fig. 1). No pathological arrhythmias were detected.
All rides induced a significant HR increase $(p<0.001)$. Different effect on HR of speed $v s \mathrm{~g}$ was also investigated. Maximum HR on Ride 1, with higher speed but lower $\mathrm{g}$ compared to Ride 4, was higher by 20 [95 \% CI 9-30] $\mathrm{b} \min ^{-1}, p<0.001$. Ride length did not affect the degree of tachycardia.

Overall, there was a slight tendency for boys to have lower maximum HR than girls (difference -11 [ -28 to 7] b $\min ^{-1}, p=0.23$ ) (Table 1; Fig. 1).

There was a significant anticipatory tachycardia (mean difference from resting $\mathrm{HR} 46$ [41-51] $\mathrm{b} \mathrm{min}^{-1}$, $p<0.001)$ in $96 \%$ of data points. Anticipatory HR was lower in boys than in girls (difference $-18[-28$ to -8$]$ $\left.\mathrm{b} \min ^{-1}, p=0.001\right)$.

$\mathrm{HR}$ at $10 \mathrm{~min}$ recovery was significantly higher than resting HR (difference 44 [39-49] $\mathrm{b} \mathrm{min}^{-1}, p<0.001$ ). There were no differences in mean HR at 10 min recovery between Rides 1-3, although it was slightly higher for Ride 4 with the highest $\mathrm{g}$ compared to Ride 1 (difference 14 [1-26] $\left.\mathrm{b} \mathrm{min}^{-1}, p=0.03\right)$. Recovery HR was also lower in boys than in girls (difference $-12[-23$ to -1$] \mathrm{b} \mathrm{min}^{-1}$, $p=0.03$ ) (Table 1).

\section{Discussion}

The aim of this study was to investigate the cardiovascular stress elicited during rollercoaster rides in young boys and girls. Specifically, we recorded 2-lead ECG traces to establish the incidence of any atrial and ventricular ectopics, paroxysmal supraventricular tachycardia, paroxysmal atrial fibrillation or sustained ventricular tachycardia. Although this is a small study, it is the first report of the effects of high speed and high $g$ on HR response and arrhythmia induction in healthy children participating in a high $\mathrm{g}$ roller coaster. This lack of paediatric data is surprising considering the numbers of riders annually in theme parks around the world.

Our results showed a significant increase in HR during rollercoaster rides from baseline resting HR ( $p<0.001$ for all rides), the levels of which are comparable to HR during moderate exercise. Although sudden sympathetic activation, as experienced on roller coasters, is one mechanism of pathological arrhythmia induction, in contrast to adult studies, we have, however, not observed any episodes of abnormal rhythm in children. However, significant sinus tachycardia occurred in $95 \%$ of children which is a much higher frequency than the $44 \%$ reported in adults [7].

Remarkably, a tachycardic response was not confined to periods on rides, but we recorded significant $(p<0.001)$ tachycardia $5 \mathrm{~min}$ before the ride indicating that part of the tachycardia effect is not related to speed or $g$ but is an anticipatory response, which was more pronounced in girls. 


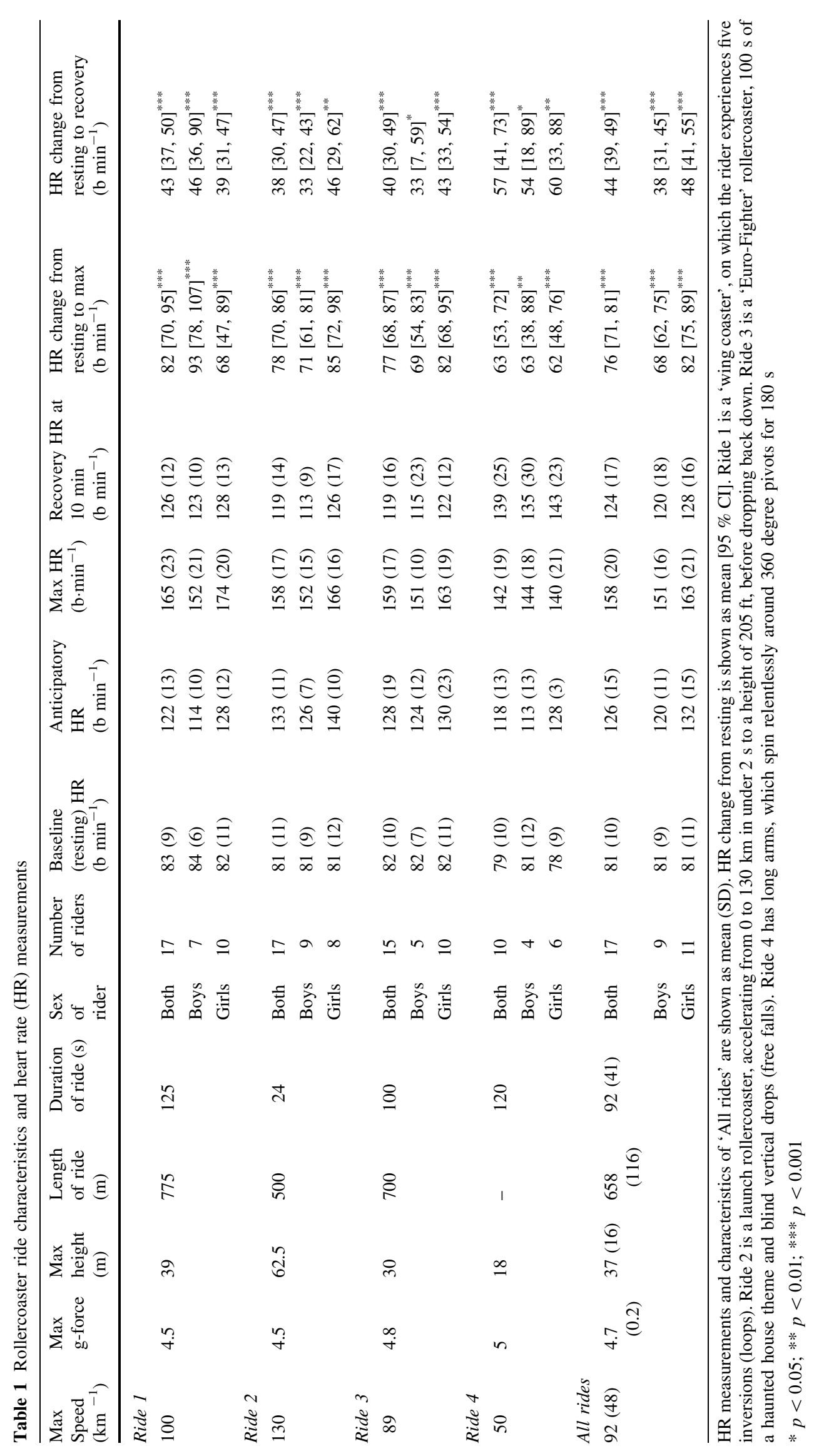


Fig. 1 HR measurements (resting, anticipatory, maximal and 10 min recovery) across the four rollercoaster rides

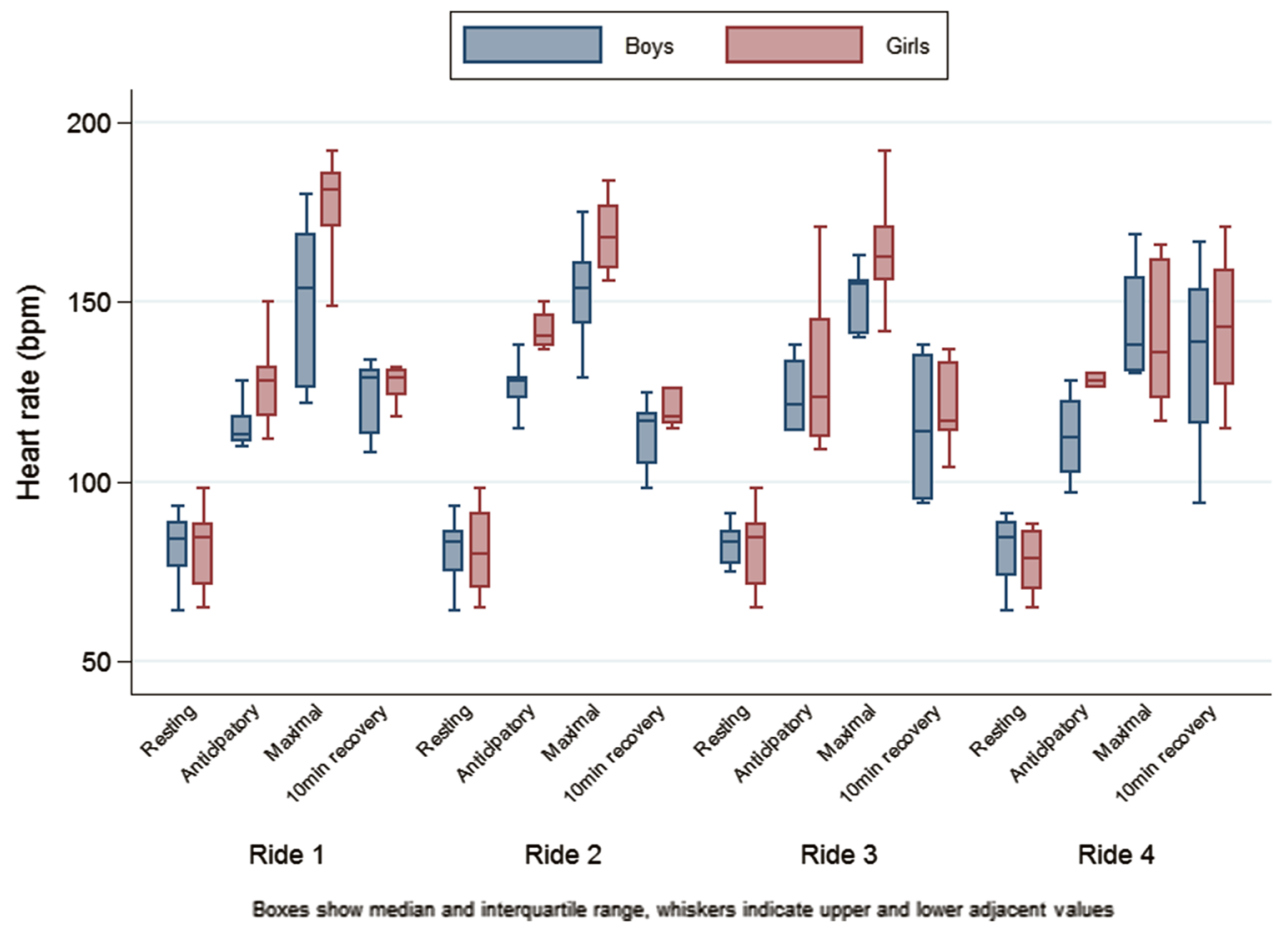

We also investigated the differential effects of speed and g on HR response. Rollercoaster rides with the highest speeds (rides 1 and 2) evoked a more pronounced tachycardia response than rides with higher $\mathrm{g}$ (rides 3 and 4). This suggests that acceleration to a greater maximal speed might play a greater part in triggering tachycardia than the effect of the $g$ exerted. In contrast, a higher $g$ but lower speed had a negative effect on HR recovery (Table 1). Sample size was a limitation.

\section{Conclusion}

This pilot study showed for the first time that there is significant sinus tachycardia, but no arrhythmia induction in response to anticipation, stress, catecholamine release and $\mathrm{g}$ exerted by modern theme park rides in healthy children. Permission to participate in rollercoaster rides and similar fairground activities is often sought by families of children with a variety of medical conditions. Although this is a small study, we hope that the detailed data obtained can help the paediatrician to give more informed advice.

Acknowledgments This work was supported by the National Institute for Health Research (NIHR) Biomedical Research Unit in Cardiovascular Disease at the University Hospitals Bristol NHS Foundation Trust and the University of Bristol. Dr Pieles is the holder of an NIHR Academic Clinical Lectureship in Paediatric Cardiology. We would like to thank Novacor Ltd (Swanley, Kent, UK) for providing portable ECG monitoring equipment and Thorpe Park (Merlin
Entertainments PLC, Poole, Dorset, UK) for their support during data acquisition. We thank all of the children and their families for participating in this study.

\section{Compliance with Ethical Standards}

Conflict of interest The authors have no commercial or other associations that might pose a conflict of interest in connection to the submitted article. The authors had full control of the design of the study, methods used, outcome parameters, analysis of the data and production of the manuscript.

Ethical approval All procedures performed were in accordance with the ethical standards of the institutional research committee and with the 1964 Helsinki Declaration and its later amendments or comparable ethical standards.

Informed consent Informed consent was obtained from all individual participants included in the study (written consent from parents and written assent from children).

Open Access This article is distributed under the terms of the Creative Commons Attribution 4.0 International License (http://crea tivecommons.org/licenses/by/4.0/), which permits unrestricted use, distribution, and reproduction in any medium, provided you give appropriate credit to the original author(s) and the source, provide a link to the Creative Commons license, and indicate if changes were made.

\section{References}

1. TEA/AECOM (2014) Theme Index \& Museum Index: The Global Attractions Attendance Report. Themed Entertainment Association (TEA), Burbank, CA 
2. National Safety Council (2014) Fixed-site Amusement Ride Injury Survey, 2013 Update. NSC Research and Statistical Services Group, Itasca, IL

3. Pelletier AR, Gilchrist J (2005) Roller coaster related fatalities, United States, 1994-2004. Inj Prev 11:309-312

4. Wu B, Xue Y, Wu P, Gu Z, Wang Y, Jing X (2012) Physiological responses of astronaut candidates to simulated $+\mathrm{Gx}$ orbital emergency re-entry. Aviat Space Environ Med 83:758-763
5. Hanada R, Hisada T, Tsujimoto T, Ohashi K (2004) Arrhythmias observed during high-G training: proposed training safety criterion. Aviat Space Environ Med 75:688-691

6. Pringle SD, Macfarlane PW, Cobbe SM (1989) Response of heart rate to a roller coaster ride. BMJ 299:1575

7. Kuschyk J, Haghi D, Borggrefe M, Brade J, Wolpert C (2007) Cardiovascular response to a modern roller coaster ride. JAMA 298:739-741 